\title{
Sensitivity Analysis and Error Analysis of Reflectance Based Vicarious Calibration with Estimated Aerosol Refractive Index and Size Distribution Derived from Measured Solar Direct and Diffuse Irradiance as well as Measured Surface Reflectance
}

\author{
Kohei Arai ${ }^{1}$ \\ Graduate School of Science and Engineering \\ Saga University \\ Saga City, Japan
}

\begin{abstract}
Sensitivity analysis and error of reflectance based vicarious calibration with estimated aerosol refractive index and size distribution derived from measured solar direct and diffuse irradiance as well as measured surface reflectance is conducted for solar reflective channels of mission instruments onboard remote sensing satellites. Through these error analyses, it is found that the most influencing factor is surface reflectance. The most significant 75 to $91 \%$ of vicarious calibration coefficients error is due to surface reflectance followed by atmospheric optical depth and Junge parameter. Therefore, we have to care about surface reflectance measuring accuracy followed by atmospheric optical depth (aerosol refractive index, and water vapor and ozone absorption) and Junge parameter (aerosol size distribution). As a conclusion, it is confirmed that surface reflectance is most influencing factor on TOA radiance. When the atmospheric optical depth is small, then Junge parameter is influencing.
\end{abstract}

Keywords-Vicarious calibration; Top of Atmosphere Radiance; At sensor Radiance; refractive index; size distribution; Junge parameter; optical depth

\section{INTRODUCTION}

Vicarious calibration for solar reflective channels of mission instruments onboard remote sensing satellites, visible and Near Infrared radiometers and short-wavelength infrared radiometers is widely ation thermometer, Alternative calibration using measurement data on the ground and onboard calibration by the calibration mounting system is performed. For example, Marine Observation Satellite-1 [1], Landsat-7 Enhanced Thematic Mapper Plus [2], SeaWiFS [3], High Resolution Visible: HRV/SPOT-1 and 2 [4], Hyperion [5], POLDER [6], etc. by ASTER [7]. The calibration results and the like have been reported. Further, report according to reciprocity with a uniform ground surface [8] over a wide area such as desert radiometer each other overlapping of the observation wavelength range have been made [9].
Vicarious calibration can be divided into approaches that are based on the radiance method based on reflectivity. The former to compute the calibration coefficients by the basis of the measurement data of the thickness atmospheric optical instruments from the ground surface reflectance and was placed on the ground, to estimate the atmospheric upper radiance, and compared with satellite radiometer data the contrast, estimates the upper atmospheric radiance also using the vertical measurement data of the thickness atmospheric optical equipped aircraft or the like, the latter is compared with satellite radiometer data. After the latter requires a lot of costs, there is also a problem of the calibration accuracy of the radiometer mounted on an aircraft, the former is generally used.

In order to clarify sensitivities of the parameters which are influencing to vicarious calibration accu5racvy, sensitivity analysis is conducted. It is well reported that the most influencing parameter on vicarious calibration accuracy is surface reflectance. Therefore, an error analysis is conducted for surface reflectance on vicarious calibration accuracy.

The next section describes the method for sensitivity analysis and error analysis together with specific parameters of vicarious calibration in particular for ASTER/VNIR which is onboard on Terra satellite of the first earth observation satellites of EOS project which is lead by NASA. Then the results from sensitivity analysis and error analysis are described followed by conclusion and some discussions.

\section{PROPOSED METHOD}

\section{A. Reflectance based vicarious calibration method}

This section briefly describes the reflectance-based method used in this work and reminds the reader how this method is applied to solar reflection spectral channels of mission instruments onboard remote sensing satellite. Most of calibration teams use the reflectance-based approach, but 
differences in the specific application of the method exist. The basic philosophy of the reflectance-based approach relies on ground-based, surface reflectance measurements of a selected site. These test sites are described in the following section. The results of the ground-based measurements are input into a radiative transfer code. Inherently, the radiative transfer codes are solar irradiance models that allow for the conversion of relative radiance (can be viewed as reflectance) to absolute radiance. The solar model for the current work is based on the World Radiation Center (WRC) model. This solar model was selected by most of calibration teams. The importance of this is that results can differ significantly based on the solar model that is chosen. Once the at-sensor, hyperspectral, absolute radiances are determined; they are band-averaged across the sensor spectral response to give a predicted, at-sensor, spectral radiance for the specific band of interest. This absolute radiative transfer code output is compared to that from the sensor to derive the calibration or to validate the reported atsensor radiance.

The target mission instrument for sensitivity analysis and error analysis is ASTER/VNIR which is onboard on Terra satellite. ASTER/VNIR is visible to Near Infrared Radiometer with 15 meter of Instantaneous Field of View: IFOV. Wavelength coverage of each spectral wavelength band is shown in Table 1. Table 2 lists the high and normal gains as well as the band-averaged center wavelength for the VNIR bands of ASTER. Also unit conversion coefficients which allow convert from Digital Number: DN of ASTER/VNIR output to radiance in unit of $\mathrm{W} / \mathrm{m}^{2}$ str $\mu \mathrm{m}$ are listed in Table 3.

TABLE I. WAVELENGTH COVERAGE OF ASTER/VNIR

\begin{tabular}{|c|c|}
\hline Spectral Band & Wavelength Coverage \\
\hline Band1 & $0.52 \sim 0.60 \mu \mathrm{m}$ \\
\hline Band2 & $0.63 \sim 0.69 \mu \mathrm{m}$ \\
\hline Band3 & $0.76 \sim 0.86 \mu \mathrm{m}$ \\
\hline
\end{tabular}

TABLE II. LIST THE HIGH AND NORMAL GAINS AS WELL AS THE BANDAVERAGED CENTER WAVELENGTH FOR THE VNIR BANDS OF ASTER.

\begin{tabular}{|c|c|c|c|c|}
\hline \multirow{2}{*}{ Band No. } & \multicolumn{4}{|c|}{ Maximum Radiance $\left(\mathrm{W} / \mathrm{m}^{2}\right.$ str $\left.\mu \mathrm{m}\right)$} \\
\cline { 2 - 5 } & High Gain & Normal Gain & Low Gain 1 & Low Gain 2 \\
\hline 1 & 170.8 & 427 & 569 & N/A \\
\hline 2 & 179.0 & 358 & 477 & N/A \\
\hline 3 & 106.8 & 218 & 290 & N/A \\
\hline
\end{tabular}

TABLE III. CALCULATED UNIT CONVERSION COEFFICIENTS: UCC

\begin{tabular}{|c|c|c|c|c|}
\hline \multirow{2}{*}{ Band No. } & \multicolumn{4}{|c|}{ Conversion Coefficients $\left(\mathrm{W} / \mathrm{m}^{2}\right.$ str $\left.\mu \mathrm{m}\right)$} \\
\cline { 2 - 5 } & High Gain & Normal Gain & Low Gain 1 & Low Gain 2 \\
\hline 1 & 0.676 & 1.688 & 2.25 & N/A \\
\hline 2 & 0.708 & 1.415 & 1.89 & N/A \\
\hline 3 & 0.423 & 0.862 & 1.15 & N/A \\
\hline
\end{tabular}

\section{B. Test sites}

The joint field campaigns for ASTER took place at Ivanpah Playa, California and Railroad Valley Playa in Nevada. These test sites have been described in detail elsewhere and their descriptions are not given here. Both sites are clay-dominated dry lakes and have been used for other sensors after the mid-1990s. The Ivanpah Playa is a hard surface. It is located south of Las Vegas, Nevada on the California-Nevada border. Figure 1(a) shows ASTER/VNIR image of the test site of Ivanpah playa while Figure 1 (b) shows a portion of ASTER/VNIR image of Alkali Lake test site. Also, Figure 1(c) shows ASTER/VNIR image of the Railroad Valley Playa test site.

These test sites are selected due to the fact that these are widely situated and homogeneous and also are situated at relatively high elevation (thin atmosphere). These are accessible comparatively easily.
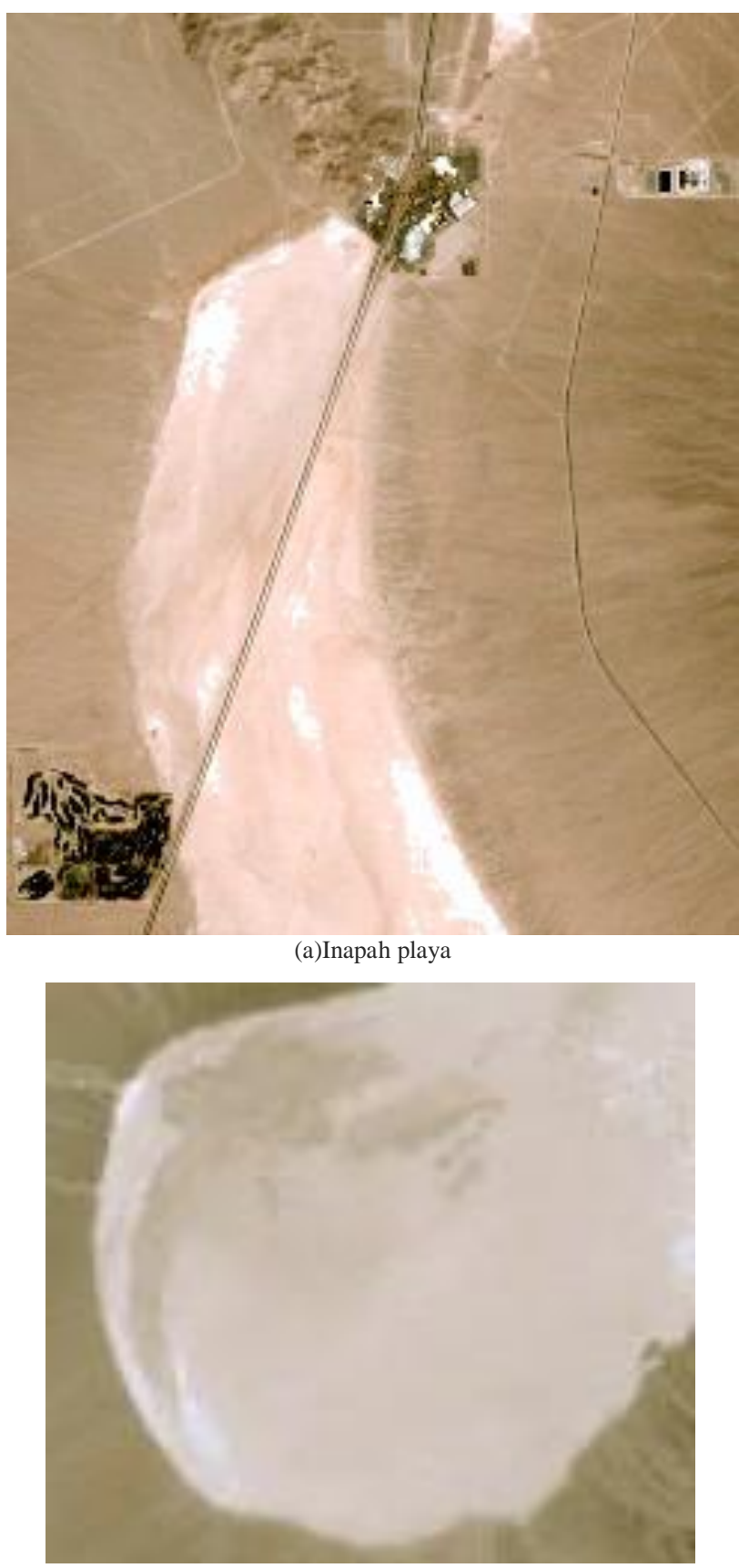

(b)Alkali Lake 


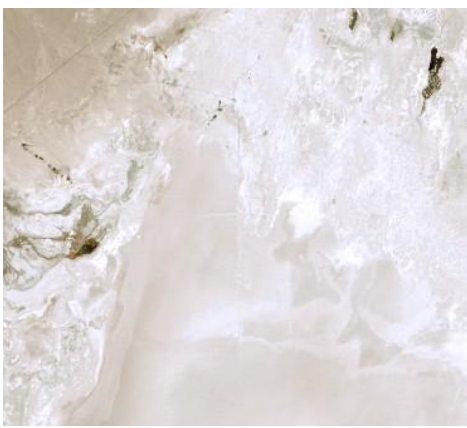

(c)Railroad Valley Playa

Fig. 1. Test sites for vicarious calibration

\section{Method}

As described above, the reflectance-based approach relies on measurements of the surface reflectance and atmospheric properties at the time of the sensor overpass. The calibration team determines the reflectance of the test site by transporting a spectral-radiometer across a rectangular test site that is $80 \mathrm{~m}$ by $300 \mathrm{~m}$ in size with the longer side being perpendicular to the along-track direction of the Terra platform. The primary instrument for the surface-reflectance collection is a commercially-available spectrometer that reports output at 1$\mathrm{nm}$ intervals across the $350-2500 \mathrm{~nm}$ spectral range. Reflectance of the site is determined by ratioing the measurements of the site to those of a reference panel for which the bi-directional reflectance factor has been determined in the laboratory.

The second piece of information needed in the reflectancebased method is a characterization of the atmosphere. The solar radiometer is relatively calibrated immediately prior to, during, or after each field campaign via the Langley method and this allows for the determination of spectral atmospheric optical depths. The optical depth results are used as part of an inversion scheme to determine ozone optical depth and an aerosol size distribution. The aerosols are assumed to follow a power law distribution, also referred to as a Junge distribution. Columnar water vapor is derived from the solar extinction data using a modified-Langley approach.

The atmospheric and surface data are used in a radiative transfer code. There are a variety of codes available that all satisfy the requirements of predicting the at-sensor radiance to the required accuracy. The radiative transfer code used is MODTRAN which assumes a plane-parallel, homogeneous atmosphere and divides this atmosphere into layers to account for the vertical distribution of scatterers and weak absorption due to ozone in the visible and near infrared (approximately the 400 to $800 \mathrm{~nm}$ spectral range known as the Chappuis absorption band). The Junge parameter described in the previous section that is derived from the solar radiometer measurements is used to compute Mie scattering phase functions used in the code. The surface in this work is assumed to be Lambertian. The near-nadir view for the majority of the ASTER overpasses reduces the uncertainty of this assumption after the dominant direct-reflected solar irradiance is correctly taken into account.

Strong gaseous absorption effects due to water vapor are determined using MODTRAN to compute transmittance for the sun-to-surface-to-satellite path for 1-nm intervals from 350 to $2500 \mathrm{~nm}$. This sun-to-ground-to-sensor transmittance is multiplied by the at-sensor radiance output from the radiative transfer code to correct the radiances for this strong absorption.

Meanwhile, this approach is an approximation that excludes interactions between diffusely-scattered radiances and absorption; it does not cause large uncertainties for application to ASTER because of the small effect of absorption within most of the bands and the typically high surface reflectance of the test sites used in this work.

\section{RESULTS FROM SENSITIVITY ANALYSIS AND ERROR ANALYSIS}

\section{A. Radiometric Calibration Coefficients: RCCs}

Radiometric Calibration Coefficients: RCCs calculated with onboard calibration data and RCCs estimated with vicarious calibration data are plotted in Figure 2 together with difference between onboard and vicarious RCCs (D).

RCC

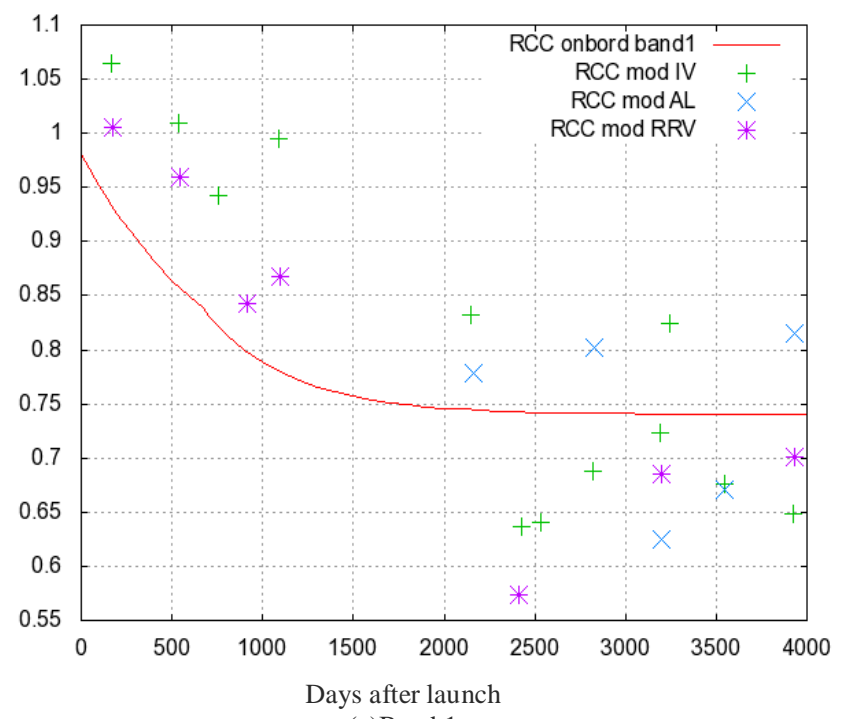

RCC

(a)Band 1

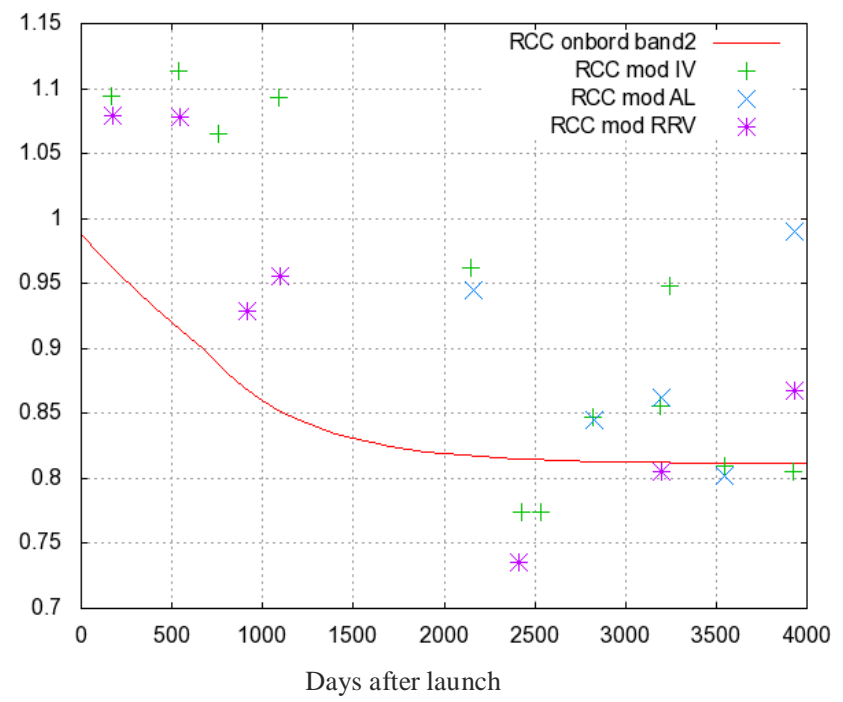

(b)Band 2 
RCC

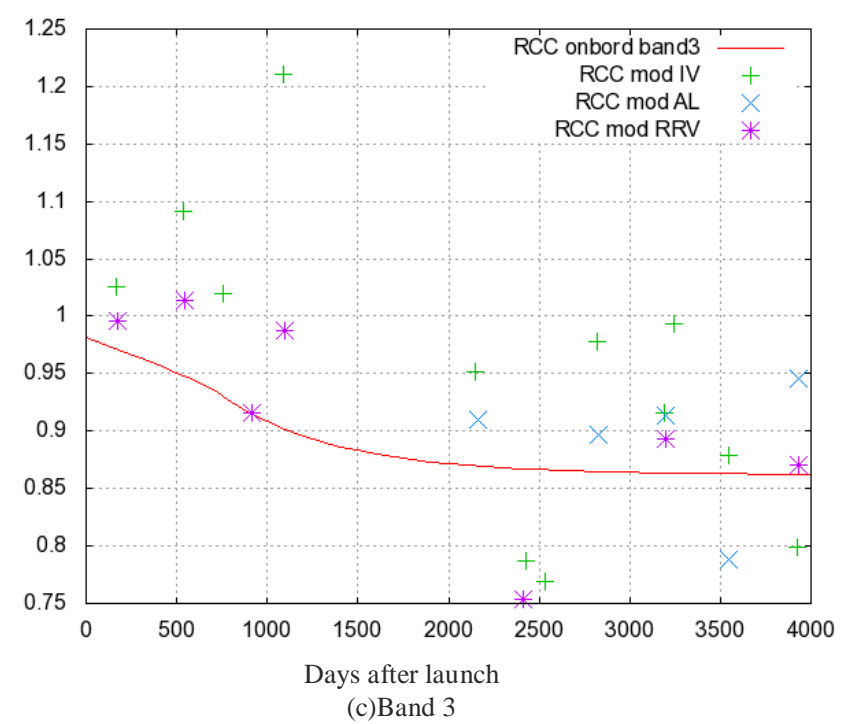

RMSD

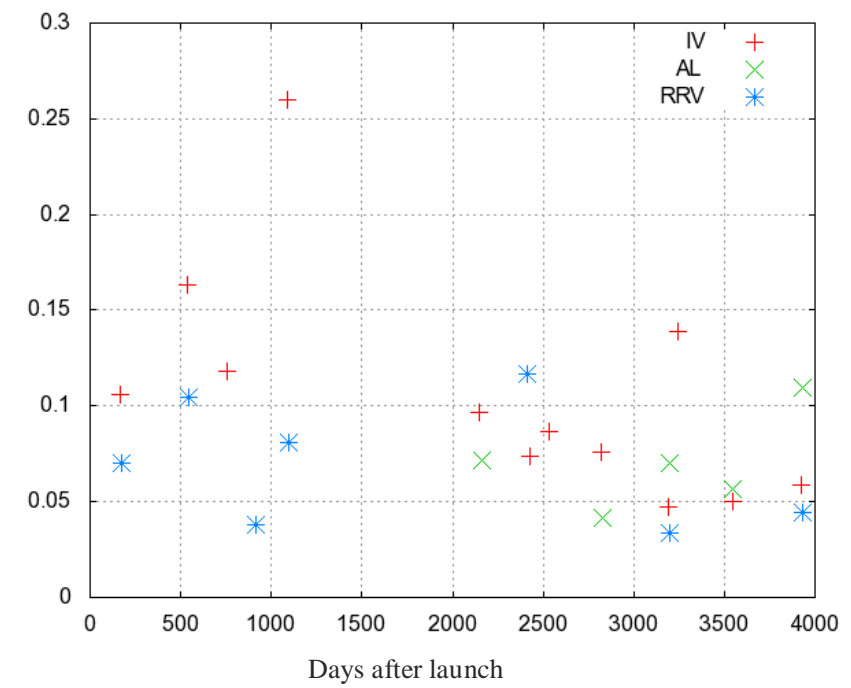

(d)Root Mean Square Difference: RMSD between vicarious and onboard calibration coefficients

Fig. 2. Trends of onboard and vicarious calibration coefficients and the dereference between both

\section{B. Sensitivity Analysis}

Vicarious calibration accuracy depends on surface reflectance, atmospheric optical depth measurement, solar direct and diffuse irradiance atmospheric radiative transfer code etc. In order to clarify how sensitive these parameters are, .sensitivity analysis with actual measured data which are acquired at Ivanpah playa in California, U.S.A. on September 14 2008. Major atmospheric parameters, Junge parameter, atmospheric optical depthy at $500 \mathrm{~nm}$ are as follows,

Junge parameter: 3.2

Atmospheric optical depth: 0.23

Top of the Atmosphere: TOA radiance (At Sensor Radiance) is calculated with the variables of surface reflectance, Atmospheric optical depth and Junge parameters. Figure 3 (a) shows the calculated TOA radiance with constant optical depth and the variables of surface reflectance and
Junge parameters ranges from -50 to $+50 \%$ for Band 1 while that for Band 2 is shown in Figure 3 (b).
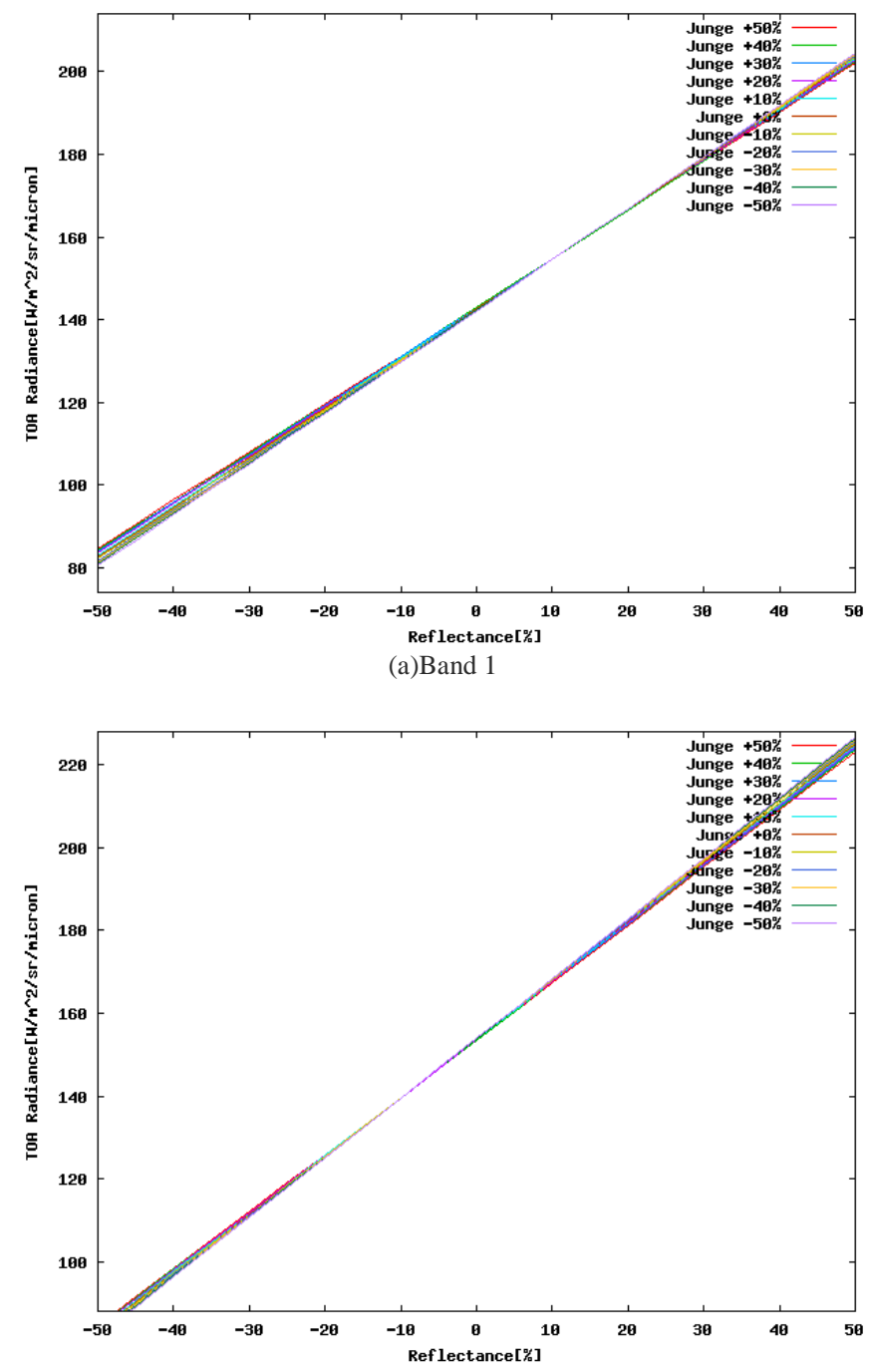

(b) Band 2

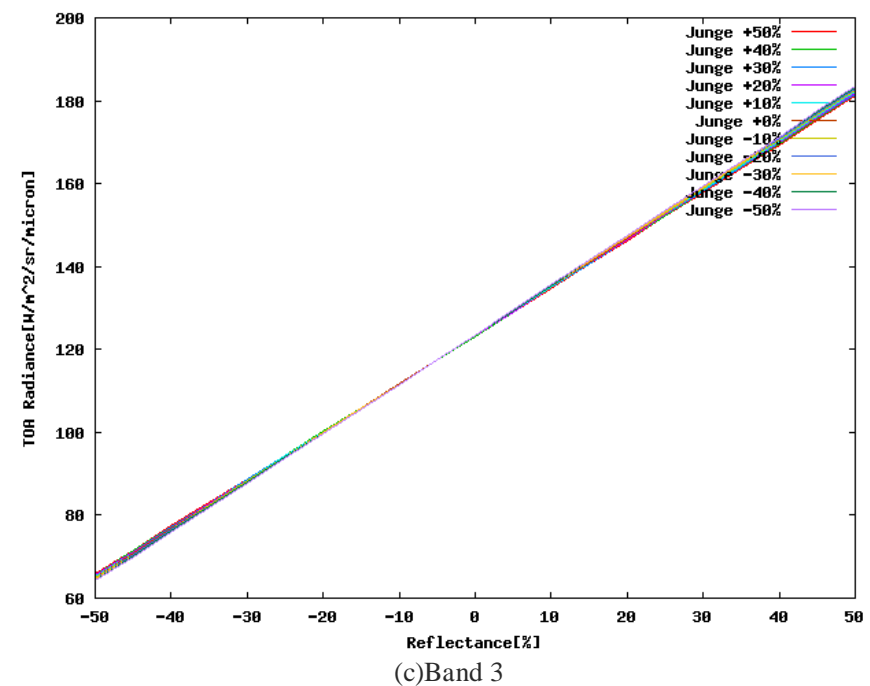

Fig. 3. Results from sensitivity analysis on TOA radiance with constant optical depth and the variables of surface reflectance and Junge parameter 
On the other hand, Figure 3 (c) shows the results from sensitivity analysis for Band 3.

Meanwhile TOA radiance calculated with constant Junge parameter and with variables of atmospheric optical depth and surface reflectance is shown in Figure 4. Figure 4 (a) is for Band 1 while Figure 4 (b) is for Band 2. Furthermore, Figure 4 (c) is for Band 3.

On the other hand, TOA radiance calculated with constant surface reflectance and with variables of atmospheric optical depth and Junge parameter is shown in Figure 5. Figure 5 (a) is for Band 1 while Figure 5 (b) is for Band 2. In addition, Figure 5 (c) is for Band 3.

As a conclusion, it is confirmed that surface reflectance is most influencing factor on TOA radiance. When the atmospheric optical depth is small, then Junge parameter is influencing.

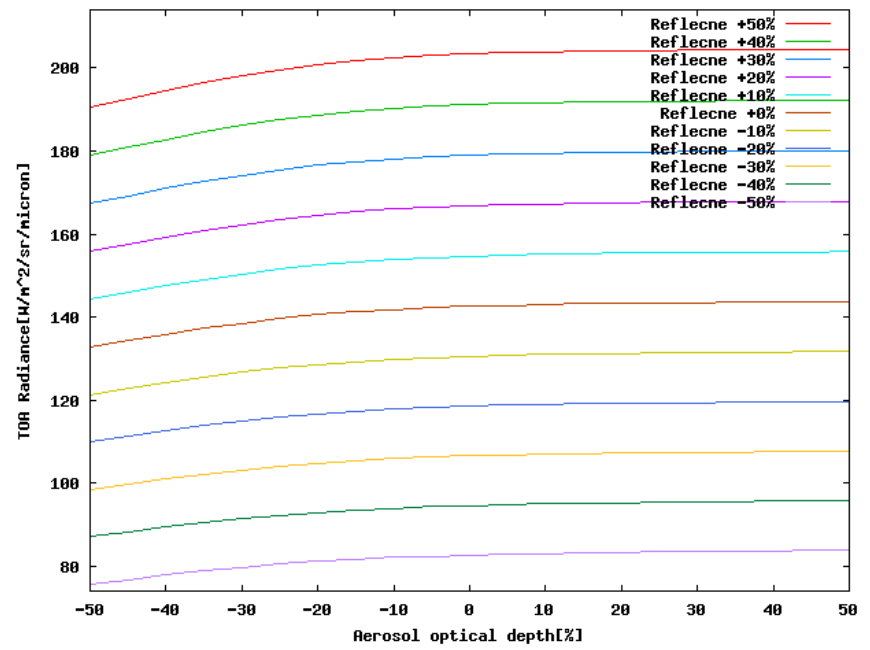

(a)Band 1

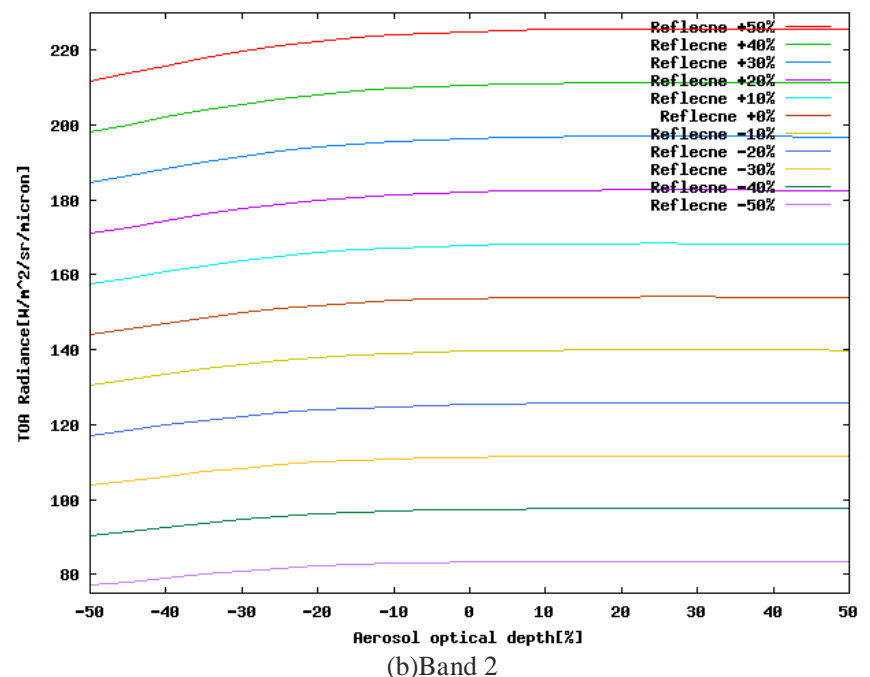

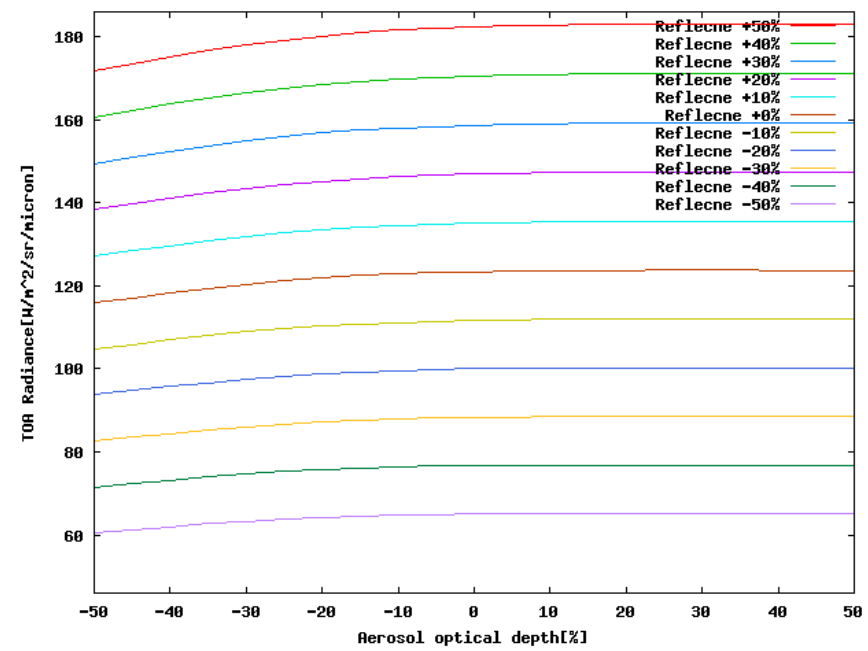

(c)Band 3

Fig. 4. Results from sensitivity analysis on TOA radiance with constant Junge parameter and with variables of optical depth surface reflectance

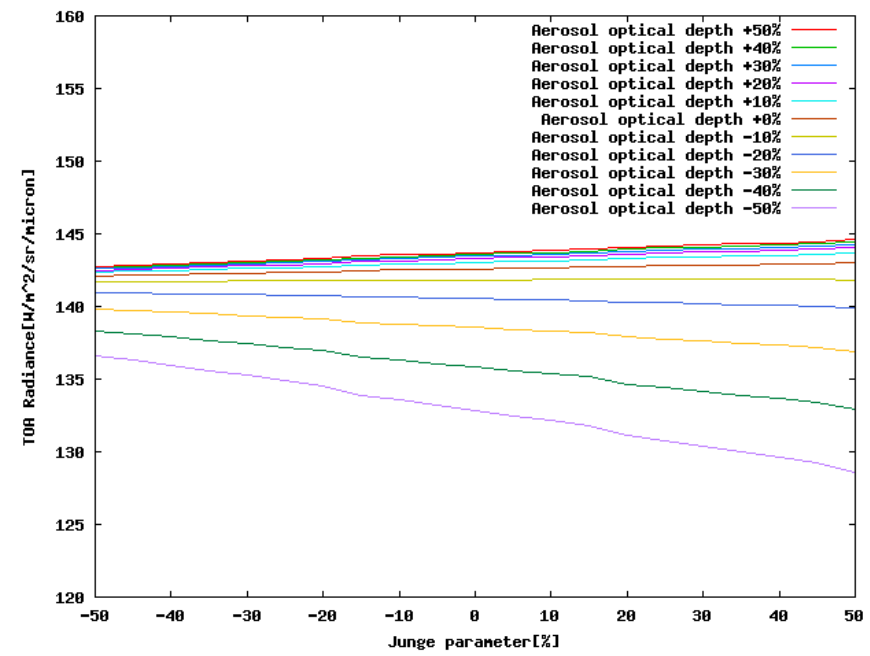

(a)Band 1

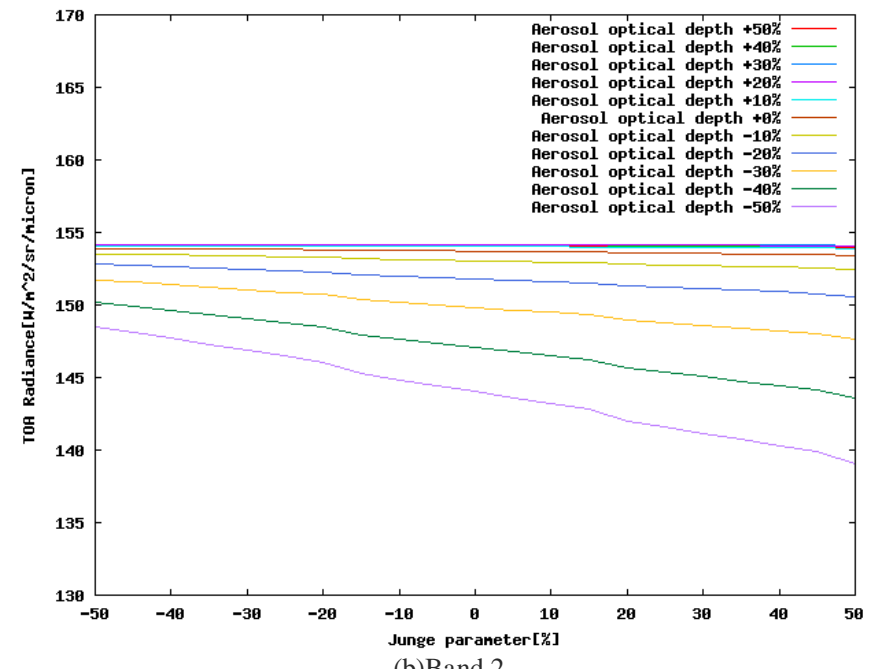




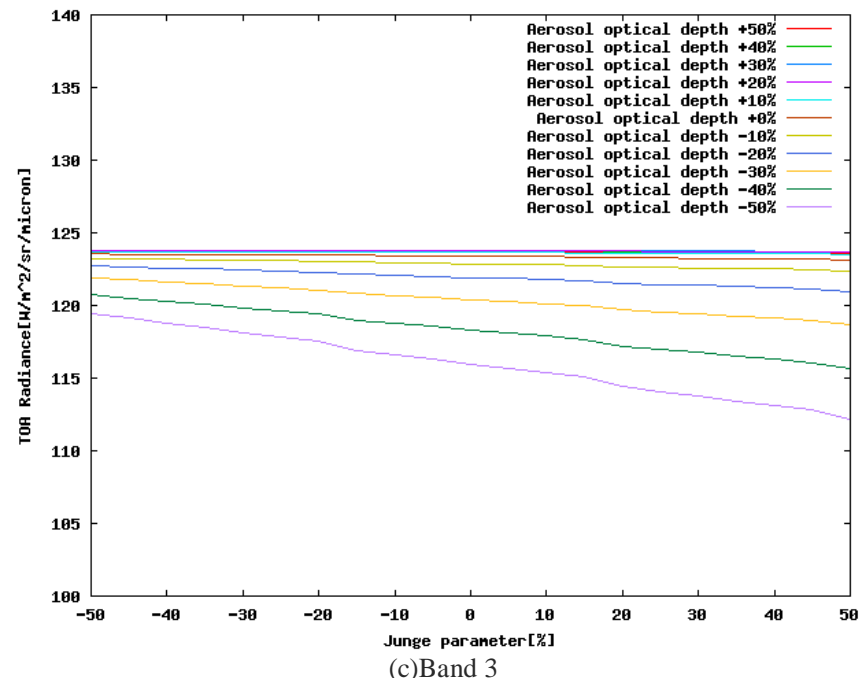

Fig. 5. Results from sensitivity analysis on TOA radiance with constant Surface reflectance and with the variables of optical depth and Junge parameter

\section{Error Analysis}

Error analysis is conducted with $+/-5 \%$ of intentional error on surface reflectance.

$\mathrm{RCC}$

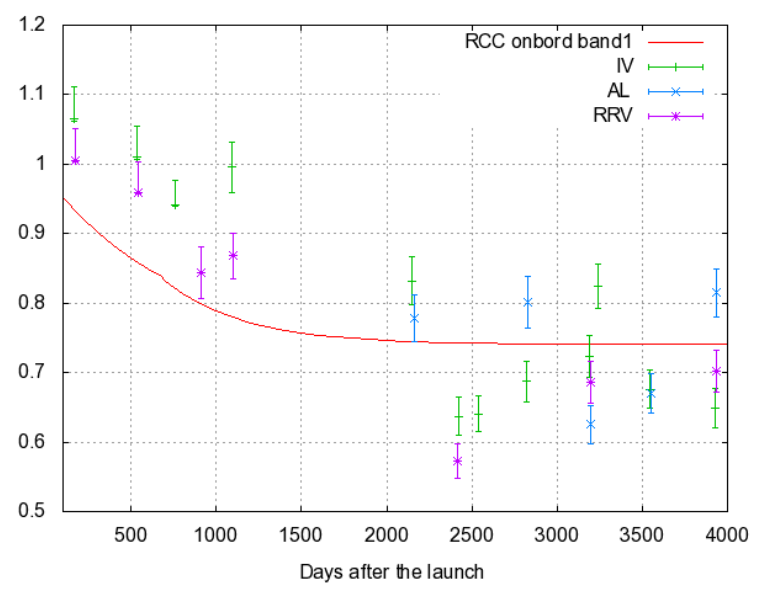

(a)Band 1

RCC

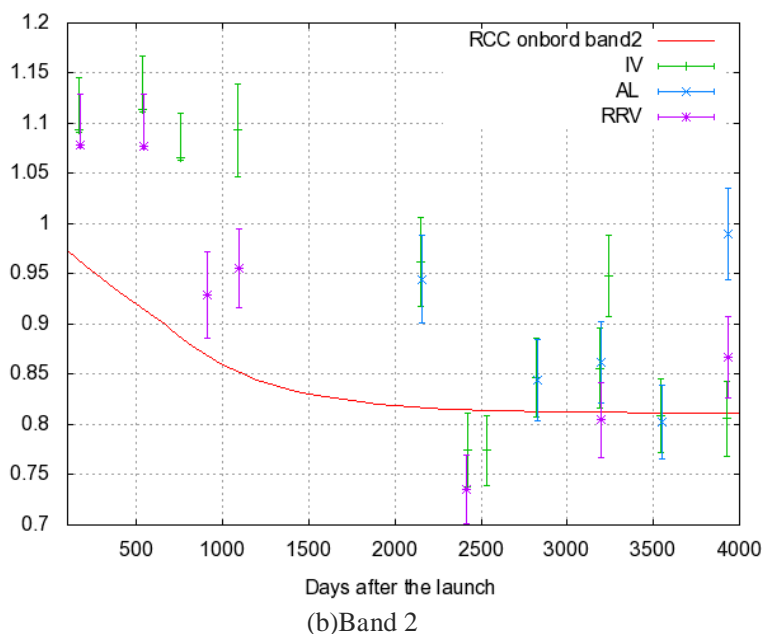

RCC

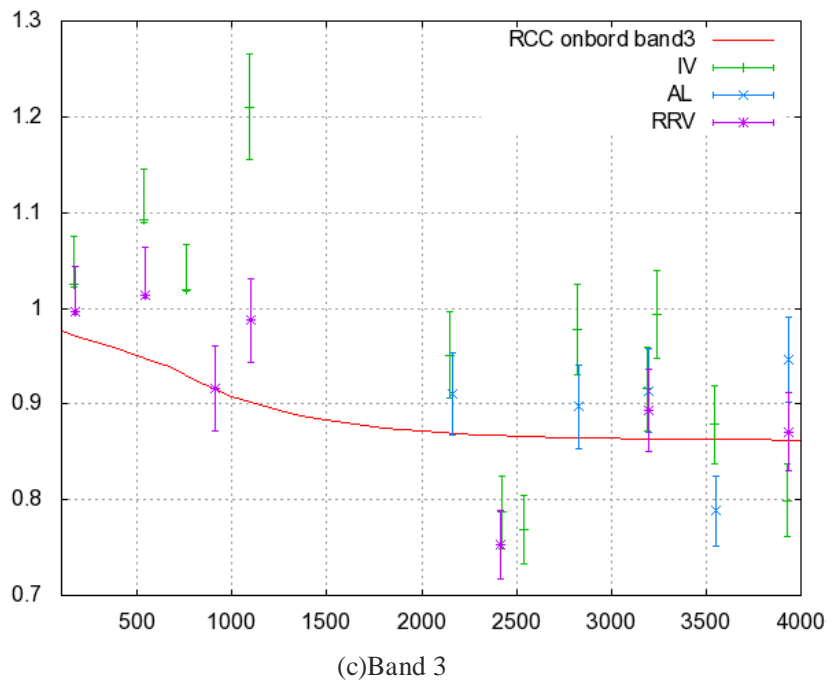

Fig. 6. Results from error analysis of vicarious calibration

Figure 6 (a), (b), (c) shows RCC with $+/-5 \%$ of error bar of Band 1, 2, and 3, respectively. From the error analysis, it is found that $+/-5 \%$ of surface reflectance error corresponds to $3.75 \%$ to $+4.54 \%$ of TOA radiance error. It is also found that $75 \%$ to $91 \%$ of vicarious calibration error is caused by surface reflectance error.

\section{Discrepancy between Onboard Calibration Coeffieint and Vicairous Clabration Coefficient}

Red solid lines in Figure 6 show RCC derived from Onboard Calibration: OBC data while green, blue and purple lines show vicarious calibration coefficients with error bars.

Therefore, discrepancy between RCC derived from OBC data and vicarious calibration data is evaluated with error bars. Figure 7 shows the evaluated result of discrepancy between RCCs in terms of Root Mean Square: RMS error.

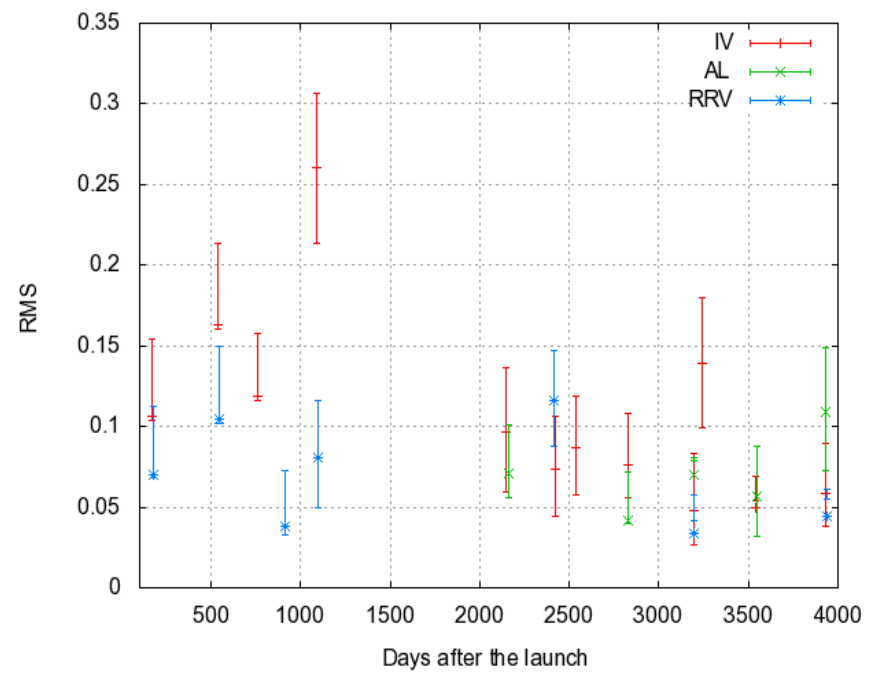

Fig. 7. Discrepancy between RCCs in terms of Root Mean Square: RMS error. 
RMS error of the vicarious calibration coefficients is summarized with its mean and $+/-5 \%$ of surface reflectance error as shown in Table 4.

TABLE IV. RMS ERROR OF THE VICARIOUS CALIBRATION COEFFICIENTS IS SUMMARIZED WITH ITS MEAN AND +/-5\% OF SURFACE REFLECTANCE ERROR

\begin{tabular}{|c|c|c|c|}
\hline RMS & Mean & $5 \%$ & $-5 \%$ \\
\hline IV & 0.10634 & 0.12903 & 0.10036 \\
\hline AL & 0.06976 & 0.08648 & 0.06737 \\
\hline RRV & 0.06961 & 0.09067 & 0.07409 \\
\hline
\end{tabular}

Furthermore, vicarious calibration coefficients calculated with maximum surface reflectance for each band as well as averaged value are shown in Table 5.

Through these error analyses, it is found that the most influencing factor is surface reflectance. The most significant 75 to $91 \%$ of vicarious calibration coefficients error is due to surface reflectance followed by atmospheric optical depth and Junge parameter. Therefore, we have to care about surface reflectance measuring accuracy followed by atmospheric optical depth (aerosol refractive index, and water vapor and ozone absorption) and Junge parameter (aerosol size distribution).

TABLE V. VICARIOUS CALIBRATION COEFFICIENTS CALCULATED WITH MAXIMUM SURFACE REFLECTANCE FOR EACH BAND AS WELL AS AVERAGED VALUE

\begin{tabular}{|c|c|c|c|c|}
\hline MAX & band1 & band2 & band3 & average \\
\hline IV & 4.15 & 4.55 & 4.72 & 4.47 \\
\hline AL & 4.37 & 4.66 & 4.77 & 4.6 \\
\hline RRV & 4.32 & 4.6 & 4.74 & 4.55 \\
\hline average & 4.28 & 4.6 & 4.74 & 4.54 \\
\hline MIN & band1 & band2 & band3 & average \\
\hline IV & -3.15 & -3.45 & -3.59 & -3.4 \\
\hline AL & -4.36 & -4.66 & -4.77 & -4.59 \\
\hline RRV & -3.09 & -3.3 & -3.43 & -3.27 \\
\hline average & -3.53 & -3.8 & -3.93 & -3.75 \\
\hline
\end{tabular}

\section{CONCLUSION}

Sensitivity analysis and error of reflectance based vicarious calibration with estimated aerosol refractive index and size distribution derived from measured solar direct and diffuse irradiance as well as measured surface reflectance is conducted for solar reflective channels of mission instruments onboard remote sensing satellites.

The most significant 75 to $91 \%$ of vicarious calibration coefficients error is due to surface reflectance followed by atmospheric optical depth and Junge parameter. Therefore, we have to care about surface reflectance measuring accuracy followed by atmospheric optical depth (aerosol refractive index, and water vapor and ozone absorption) and Junge parameter (aerosol size distribution).

As a conclusion, it is confirmed that surface reflectance is most influencing factor on TOA radiance. When the atmospheric optical depth is small, then Junge parameter is influencing.

\section{ACKNOWLEDGMENT}

The author would like to thank Mr. Kntaro Oya for his efforts through experiments and simulations.

\section{REFERENCES}

[1] Arai K., Preliminary assessment of radiometric accuracy for MOS-1 sensors, International Journal of Remote Sensing, 9, 1, 5-12, 1988.

[2] Barker, JL, SK Dolan, et al., Landsat-7 mission and early results, SPIE, 3870, 299-311, 1999.

[3] Barnes, RA, EEEplee, et al., Changes in the radiometric sensitivity of SeaWiFS determined from lunar and solar based measurements, Applied Optics, 38, 4649-4664, 1999.

[4] Gellman, DI, SF Biggar, et al., Review of SPOT-1 and 2 calibrations at White Sands from launch to the present, Proc. SPIE, Conf.No.1938, 118125, 1993.

[5] Folkman, MA, S.Sandor, et al., Updated results from performance characterization and calibration of the TRWIS III Hyperspectral Imager, Proc. SPIE, 3118-17, 142, 1997.

[6] Hagolle, O., P.Galoub, et al., Results of POLDER in-flight calibration, IEEE Trans. On Geoscience and Remote Sensing, 37, 1550-1566, 1999.

[7] Thome, K., K. Arai, S. Tsuchida and S. Biggar, Vicarious calibration of ASTER via the reflectance based approach, IEEE transaction of GeoScience and Remote Sensing, 46, 10, 3285-3295, 2008.

[8] Cosnefroy, H., M.Leroy and X.Briottet, Selection and characterization of Saharan and Arabian Desert sites for the calibration of optical satellite sensors, Remote Sensing of Environment, 58, 110-114, 1996.

[9] Arai, K., In-flight test site cross calibration between mission instruments onboard same platform, Advances in Space Research, 19, 9, 1317-1328, 1997.

\section{AUTHORS PROFILE}

Kohei Arai, He received BS, MS and PhD degrees in 1972, 1974 and 1982, respectively. He was with The Institute for Industrial Science and Technology of the University of Tokyo from April 1974 to December 1978 also was with National Space Development Agency of Japan from January, 1979 to March, 1990. During from 1985 to 1987, he was with Canada Centre for Remote Sensing as a Post Doctoral Fellow of National Science and Engineering Research Council of Canada. He moved to Saga University as a Professor in Department of Information Science on April 1990. He was a councilor for the Aeronautics and Space related to the Technology Committee of the Ministry of Science and Technology during from 1998 to 2000 . He was a councilor of Saga University for 2002 and 2003. He also was an executive councilor for the Remote Sensing Society of Japan for 2003 to 2005 . He is an Adjunct Professor of University of Arizona, USA after 1998. He also is Vice Chairman of the Commission "A" of ICSU/COSPAR after 2008. He wrote 30 books and published 492 journal papers 